\title{
Mosque as a vaccination site for ethnic minority in Japan: leaving no one behind amid the COVID-19 pandemic
}

Hitomu Kotani ( $\sim$ kotani.hitomu.5c@kyoto-u.ac.jp )

Department of Urban Management, Graduate School of Engineering, Kyoto University, Japan https://orcid.org/0000-0002-5033-0855

Hirofumi Okai

Faculty of International Social Studies, Kyoai Gakuen University, Japan

\section{Mari Tamura}

Department of International Studies, Graduate School of Frontier Sciences, The University of Tokyo, Japan

\section{Short Report}

Keywords: coronavirus, vaccine, Muslims, Islam, disaster

Posted Date: October 22nd, 2021

DOI: https://doi.org/10.21203/rs.3.rs-1006267/v1

License: (1) (i) This work is licensed under a Creative Commons Attribution 4.0 International License. Read Full License

Version of Record: A version of this preprint was published at Disaster Medicine and Public Health Preparedness on March 23rd, 2022. See the published version at https://doi.org/10.1017/dmp.2022.78. 


\section{Abstract}

Ethnic minorities with different languages and religions are potentially vulnerable not only during natural hazard-induced disasters, but also during the COVID-19 pandemic. Their vaccination coverage may be lower, and vaccination strategies should prevent them from being left behind. This report presents the first case in Japan where a mosque, being the hub of foreign Muslims, was used as a vaccination site from the end of July 2021. The targeted mosque was Ebina Mosque in Kanagawa Prefecture, and most of the vaccine recipients were foreign Muslims. The mosque differed from other vaccination sites in that reservations could be made easily through the managers, and linguistic diversity (i.e., the mosque managers and mosque-related volunteers served as interpreters) and gender were considered. These efforts are likely to have removed some barriers to vaccination for ethnic minorities and contributed to "no one will be left behind."

\section{Introduction}

Vaccination against COVID-19 is an important measure against the pandemic. However, as is the case with natural hazard-induced disasters, where ethnic minority groups tend to be left behind due to language and religious differences ${ }^{1,2}$, there are concerns that vaccination rates among them may be lower ${ }^{3,4}$. Vaccination strategies to avoid exclusions, both for humanitarian reasons and for overall social safety, should be implemented.

Ethnic minorities in Japan are likely to be excluded from the vaccination process. To get vaccinated, people first require vaccination vouchers distributed by local governments. Then, people have three main vaccination options: (1) individual vaccination (at local hospitals or clinics), (2) group vaccination (at local gymnasiums or convention centers set up by local governments), and (3) workplace vaccination (arranged by their companies or universities). Those ineligible for workplace vaccination should make an appointment for individual or group vaccination through their local government's booking website. However, information on vaccination vouchers and booking websites is primarily written in Japanese. There are barriers prior to making a booking and accessing a vaccination site for people with limited Japanese language skills and who are unfamiliar with the Japanese medical system. Furthermore, few vaccination sites are multilingual, or culturally or religiously sensitive, which is considered a heavy psychological burden.

This report presents a case study of group vaccination at Ebina Mosque in Ebina City, Kanagawa Prefecture, Japan, that was initiated to reduce these hurdles. It is extremely rare for mosques, being the bases of an ethnic minority group, to be used as vaccination sites in Japan. As far as we know, as of October 1, 2021, Ebina Mosque and Osaka Islamic Center are the only mosques in Japan used as vaccination sites, and Ebina Mosque was the first and a large-scale case. Based on information obtained through our field survey on September 18, 2021 (observation at the site and interviews with a deputy representative of the mosque, an imam (i.e., a religious leader), and a city office worker) and emailed by 
the City Office before and after the field survey, we describe how vaccination was conducted at the mosque and how ethnic minorities were considered.

\section{Ebina Mosque As A Vaccination Site}

Ebina Mosque is a place of worship used daily by Muslims-mainly people with foreign citizenship. Even amid the COVID-19 pandemic, on weekdays, 10 to 50 Muslims attend each of the five daily prayers; on Fridays, 300 to 400 Muslims gather for mass prayers. The nationalities of the users are diverse: while a majority of them are Sri Lankans, some are Pakistanis, Bangladeshis, Indians, Fijians, and so forth. They not only live in Ebina City, but also in neighboring municipalities. The four-story mosque, newly built in 1998, has worship space on the first through third floors. It is managed and operated by a Sri Lankan representative, a deputy Pakistani representative, a Sri Lankan imam, and a Pakistani imam. It is one of 19 mosques managed by the religious corporation, Darussalam ${ }^{5}$.

Vaccination at this mosque started on Saturday, July 31, 2021. The Ebina City Office had three group vaccination sites (i.e., two gymnasiums and one convention center), but to prevent people from being unable to receive vaccinations due to language barriers, and to increase the vaccination rate in the region as a whole, the City Office planned, from late June 2021, to use the mosque, where foreign residents regularly gathered, as a vaccination site. After lobbying the mosque, the City Office executed the plan. Vaccinations occurred every Saturday and continued until October 23, 2021. Consequently, approximately 750 people associated with the mosque were vaccinated. The target population was Ebina residents first, but it was expanded to residents of neighboring municipalities. Most of the targeted people were foreign Muslims who regularly used the mosque, but a few Japanese (i.e., wives and children of foreign Muslims) and people of other religions who had a connection to the mosque were also included. Reservations were accepted at the mosque, not through the city's booking website, and were reported to the City Office by the mosque managers. Each week, approximately 100 people were vaccinated for 1.5 hours, starting at 2:00 p.m., by doctors, nurses, and paramedics entrusted by the City Office. Pfizer vaccines were used, and a 75square-meter room on the second and/or third floor was used as the vaccination site.

On the vaccination day, the reception desk opened at 1:30 p.m. The residence card and the certificate of residence of each person with a reservation were checked at the desk. Once checked, people went to the designated vaccination rooms on the second or third floor, which were well ventilated with open windows and an electric fan. They entered the rooms in order and sat down to wait. When about 30 people had gathered, a Japanese doctor explained the precautions in Japanese in front of them. After that, doctors walked around and conducted individual medical interviews. Thereafter, nurses and paramedics administered vaccinations to those who had completed the medical interview (Figure 1). After vaccination, the vaccinees waited for 15 minutes for observation. Japanese traditional bedding (futon) prepared by the mosque was placed at the back of the room in case anyone became unwell. Those whose waiting time had expired left the room. This cycle was repeated until the scheduled number of people for the day was completed. 
There were two notable aspects of vaccination at the mosque: multilingual support and gender support. For multilingual support, medical questionnaires in Japanese and English were available. Confirmation and questions about vaccination precautions (i.e., history of anaphylaxis) in Japanese, English, Tamil, Urdu, Sinhalese, and Bengali were also posted at the reception. Furthermore, three or four interpreters conversant in several foreign languages were on standby. They could interpret Japanese into not only English but also Bengali, Tamil, Sinhala, and other languages. The interpreters included volunteers from among the daily users as well as the mosque representative and imams. They interpreted beside the doctors during the initial group explanations and the individual medical interviews. Additionally, vaccine recipients were given stickers to wear, naming the language in which they were fluent (Japanese, English, Sinhalese, Tamil, and so on), enabling Japanese staff to easily determine the appropriate interpreter required by the recipients.

Support regarding gender was based on the fact that most of the vaccinees were Muslims. Measures were taken to avoid females sharing the same space with males. Specifically, the vaccination rooms were separated for women and men (i.e., women on the second floor and men on the third floor), or if they shared the same room, the women's space was separated by a curtain. Female nurses administered vaccinations to female recipients.

\section{Discussion}

This paper reported the first case in Japan where a mosque regularly used by foreigners was used as a group vaccination site for the COVID-19 vaccine. The foreigners were familiar with the mosque, they could make an appointment through those they had a relationship with, and they could receive multilingual and gender-related support on site. It is likely that these facts positively affected factors that influence vaccination ${ }^{3}$-(1) motivation to get vaccinated and (2) practical issues (e.g., access, availability, and convenience). From these perspectives, Ebina Mosque as a vaccination site probably promoted the vaccination of ethnic minorities, so that they were not left behind. It is estimated that there are approximately 180000 foreign Muslims in Japan as of $2018^{6}$, being overwhelmingly small compared to Japan's total population (i.e., approximately 130 million). As of 2017, there are approximately 100 mosques in Japan, operated mainly by foreign Muslims ${ }^{5}$. Vaccination strategies are expected to take advantage of their activity bases or networks ${ }^{7}$, and this case study is a valuable example in a Muslimminority society.

Additionally, mosques in Japan are beginning to be known for approaching not only Japanese but also foreign residents with specific needs, providing appropriate support during the COVID-19 $\mathrm{crisis}^{8}$ and natural hazard-induced disasters (e.g., earthquakes) ${ }^{9-12}$. The government and healthcare sectors should be encouraged to work closely with mosques to realize disaster management plans that avoid exclusions.

Globally, other countries and regions experience similar issues. Religious or faith-based organizations are also expected to work actively in times of disaster ${ }^{13,14}$. Hopefully, this case study will be useful to these 
areas, helping to realize a world where no one is left behind ${ }^{15}$.

\section{Declarations}

\section{ACKNOWLEDGEMENTS}

We are deeply grateful to the Ebina City Office, Ebina City Medical Association, and Ebina Mosque, which allowed us to conduct the field survey and provided us with valuable information. We also thank Yuusuke Katsura, who brought the case at the Osaka Islamic Center to our attention. This work was partly supported by the Japan Society for the Promotion of Science (KAKENHI Grant Nos. 18K13845 and 18K00085) and ISHIZUE 2021 of the Kyoto University Research Development Program.

\section{AUTHORS CONTRIBUTION}

H.K. authored the manuscript, supported by H.O. and M. T. All authors conducted the field survey, discussed the results, and contributed to the final manuscript.

\section{CONFLICTS OF INTEREST}

The authors declare no conflicts of interest.

\section{References}

1. Gaillard JC. Caste, ethnicity, religious affiliation and disaster. Routledge Handb Hazards Disaster Risk Reduction Routledge, London/New York. Published online 2012:459-469.

2. Bolin B, Kurtz LC. Race, class, ethnicity, and disaster vulnerability. In: Handbook of Disaster Research. Springer; 2018:181-203.

3. Crawshaw AF, Deal A, Rustage $K$, et al. What must be done to tackle vaccine hesitancy and barriers to COVID-19 vaccination in migrants? J Travel Med. 2021;28(4). doi:10.1093/jtm/taab048

4. Armocida B, Formenti B, Missoni E, et al. Challenges in the equitable access to COVID-19 vaccines for migrant populations in Europe. Lancet Reg Heal - Eur. 2021;6:100147.

doi:10.1016/j.lanepe.2021.100147

5. Okai H. Muslim Communities and Local Communities: Reconsidering "Multicultural Conviviality" through the Activities of Islamic Organizations [Musrimu komyunityi to chiiki shakai-Isuramu dantai no katsudou kara "tabunka kyousei" wo saikou suru]. In: Takahashi N, Shirahase T, Hoshino S, eds. Religion and Multicultural Conviviality in Contemporary Japan: Exploring the Relationship between Immigrants and Local Communities [Gendai Nihon No Shukyo to Tabunka Kyousei-Imin to Chiiki Shakai No Kankeisei Wo Saguru]. Akashi Shoten; 2018:181-203. (in Japanese) 
6. Tanada H. Estimate of Muslim Population in the World and Japan, 2018. Waseda J Hum Sci. 2019;32(2):253-262. http://hdl.handle.net/2065/00063404 (in Japanese)

7. Ali SN, Hanif W, Patel K, Khunti K. Ramadan and COVID-19 vaccine hesitancy-a call for action. Lancet. 2021;397(10283):1443-1444. doi:10.1016/S0140-6736(21)00779-0

8. Kotani $\mathrm{H}$, Tamura M, Nejima S. Mosques in Japan Responding to COVID-19 Pandemic: Infection Prevention and Support Provision.; 2021. doi:10.21203/rs.3.rs-333662/v2.

9. Nejima S, Danismaz I. Muslim NGOs and volunteers in Tohoku, Japan. In: Nejima S, ed. NGOs in the Muslim World: Faith and Social Services. Routledge; 2015:116-123.

10. Yang Z, Inagaki K, Yagi H, Yoshida S, Sadohara S. Emergency evacuation and shelter-seeking behavior of foreign residents in Kumamoto earthquake. J Disaster Res. 2017;12(sp):678-687.

11. Utaka Y. The Kobe Muslim mosque: experience of "miracles" - 1945 air raid \& 1995 earthquake. In: Selected Paper on Post-Conference Book, International Conference on Archi-Cultural Interactions through the Silk Road (IaSU2016 JAPAN).; 2017:193-197.

12. Kotani H, Tamura M, Li J, Yamaji E. Potential of mosques to serve as evacuation shelters for foreign Muslims during disasters: a case study in Gunma, Japan. Nat Hazards. Published online July 1 , 2021:1-18. doi:10.1007/s11069-021-04883-7

13. Cheema AR, Scheyvens R, Glavovic B, Imran M. Unnoticed but important: revealing the hidden contribution of community-based religious institution of the mosque in disasters. Nat Hazards. 2014;71(3):2207-2229.

14. Sheikhi RA, Seyedin H, Qanizadeh G, Jahangiri K. Role of Religious Institutions in Disaster Risk Management: A Systematic Review. Disaster Med Public Health Prep. 2021;15(2):239-254. doi:10.1017/dmp.2019.145

15. United Nations. Transforming our world: the 2030 Agenda for Sustainable Development. Published online 2015.

\section{Figures}




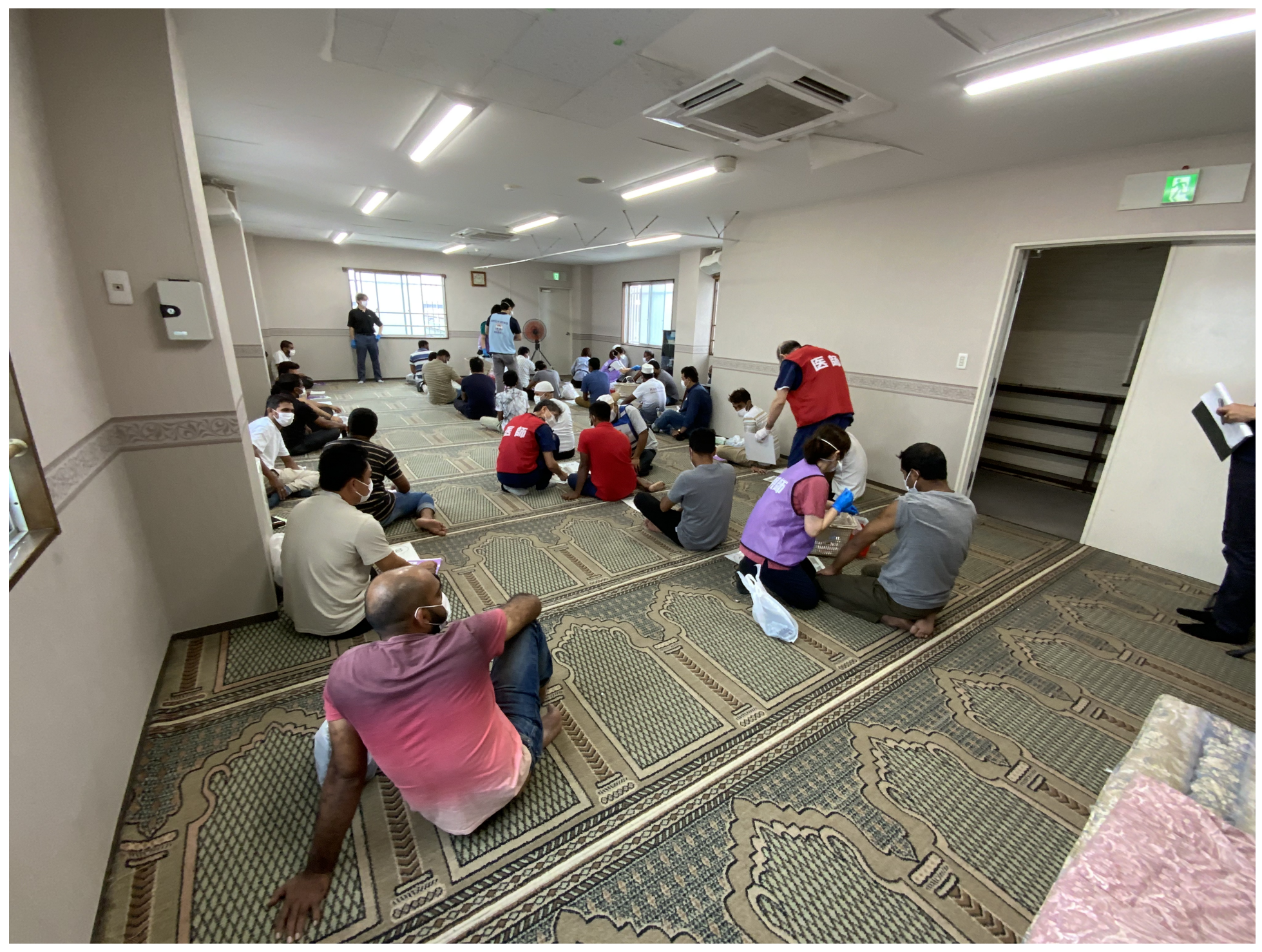

Figure 1

People receiving vaccinations on the third floor of Ebina Mosque (doctors, nurses, and paramedics wore scrimmage vests) 